\title{
De la privación a la restricción de la libertad y otras sanciones penales: ¿hacia un paradigma restaurativo en la justicia especial para la paz colombiana?*
}

\author{
From Deprivation to Restriction of Freedom and other Criminal Sanctions: Towards to a Restorative Paradigm in \\ the Special Justice for Colombian Peace?
}

Norberto Hernández Jiménez ${ }^{\text {a }}$

Pontificia Universidad Javeriana, Colombia

norbertohernandezj@javeriana.edu.co

ORCID: https://orcid.org/10.11144/Javeriana.vj69.prls
DOI: https://doi.org/10.11144/Javeriana.vj69.prls

Fecha de recepción: 07 Octubre 2019

Fecha de aprobación: 28 Octubre 2019

Fecha de publicación: 30 Junio 2020

\section{Resumen:}

El presente artículo explora los lineamientos de la sanción penal (propia, alternativa y ordinaria) como respuesta punitiva consagrada en el Acuerdo Final para la Terminación del Conflicto y la Construcción de una Paz Estable y Duradera, suscrito entre el gobierno de Colombia y las Fuerzas Armadas Revolucionarias de Colombia (FARC-EP). Para este efecto, se hace una comparación entre la jurisdicción ordinaria y la privación de la libertad en este contexto, versus la restricción efectiva de la libertad de la sanción propia y el enfoque restaurativo regulado en las leyes 1922 de 2018 (reglas de procedimiento para la Jurisdicción Especial para la Paz) y 1957 de 2019 (estatutaria de la Jurisdicción Especial para la Paz). Todo esto se enmarca en los fines de la pena y los modelos punitivos para la elección del castigo que, en virtud del contexto transicional, tiende a privilegiar la reparación frente a la retribución, aunque las sanciones alternativas y ordinarias se fundamenten en esta última contraprestación.

Palabras clave: fines de la pena, modelos punitivos, privación de la libertad, restricción de la libertad.

\section{Abstract:}

This article studies the three lines of the penal sanction (own, alternative, and ordinary) that are considered as punitive answers in the Colombian peace agreement signed by the Colombian government and the Revolutionary Armed Forces of Colombia (FARC-EP). To do so, a comparison is made between ordinary jurisdiction and the deprivation of liberty in this context, versus the effective restriction of the liberty of the sanction itself and the restorative approach. The restorative approach is regulated in two laws: (i) 1922 of 2018 (procedural rules for the Special Peace Jurisdiction) and (ii) 1957 of 2019 (statutory for the Special Peace Jurisdiction). In the transitional context determined by the peace agreement, these two laws tend to prioritize reparation over retribution regarding the theory of the purpose of punishment and the theory of punitive models. However, the alternative and ordinary sanctions are based on this last consideration.

Keywords: purposes of punishment, punitive models, deprivation of liberty, restriction of freedom.

\section{Introducción}

Dentro de las reglas de procedimiento para la Jurisdicción Especial para la Paz (Ley 1922 de 2018) se consagra como principio rector la "efectividad de la justicia restaurativa" como herramienta de consolidación de una paz estable y duradera, dentro de un enfoque que se preocupa por la satisfacción de los derechos de las víctimas ${ }^{[1]}$ del conflicto armado, que busca su reparación, concretar las garantías de no repetición y esclarecer la verdad de lo acontecido. Dentro de esta dinámica, la sanción penal se ve obligada a mutar su administración tradicional, enmarcada dentro de un modelo proporcionalista, por un modelo reparador -tercera vía del

Notas de autor

a Autor de correspondencia. Correo electrónico: norbertohernandezj@javeriana.edu.co 
derecho penal ${ }^{[2]}$, que, por encima de la cárcel, busca resarcir el daño y abordar el conflicto que subyace a la comisión del delito ${ }^{[3]}$.

En virtud de esto último, este artículo correlaciona la privación y la restricción de la libertad con los fines de la pena y los modelos punitivos para la elección del castigo. Esto, con el fin de entender la implementación de un nuevo paradigma de sanción penal, en un contexto de justicia transicional como el colombiano ${ }^{[4]}$, que dejó una cláusula abierta tanto en el Acuerdo Final para la Terminación del Conflicto y la Construcción de una Paz Estable y Duradera [en lo sucesivo Acuerdo] como en los artículos [en lo sucesivo art./arts.] 64 y 65 de la precitada ley ${ }^{[5]}$.

El contexto de los fines de la pena y los modelos punitivos servirá para delimitar el alcance de las sanciones restaurativas y su funcionalidad como alternativa frente a una finalidad resocializadora que, en términos generales, fracasó $^{[6]}$ y una teoría retributiva ${ }^{[7]}$ que no tiene viabilidad de aplicación plena frente a una salida negociada del conflicto ${ }^{[8]}$. Adicionalmente, la teleología punitiva será fundamental como criterio de individualización de las sanciones en la coyuntura de justicia transicional, que, por supuesto, responde a una dinámica diferente y que se enfrenta con los lineamientos tradicionales de la imposición de una pena. Después, se analizan los parámetros de individualización de la sanción penal y, finalmente, se ofrecen algunas conclusiones alrededor de la implementación de estas sanciones como consecuencia del Acuerdo en aras de construir un paradigma restaurativo.

\section{Privación de la libertad vs. Restricción de la libertad}

El Código Penal colombiano [en lo sucesivo C.P.] consagra delitos bajo la estructura binaria: precepto (supuesto de hecho) y sanción (consecuencia) ${ }^{[9]}$. Aunque esta última puede verse reflejada en penas pecuniarias (como pena principal) y también se pueden imponer penas accesorias, e incluso medidas de seguridad para el caso de los inimputables, el resultado ante la actualización del supuesto de hecho descrito en la norma penal consiste preponderantemente en la privación de la libertad en un establecimiento de reclusión $^{[10]}$.

Por su parte, el Acuerdo, basado en los lineamientos de la justicia transicional, establece ciertas sanciones que riñen con la concepción tradicional de esta consecuencia jurídica ante la actualización del precepto penal. En la tabla 1 se señala esta clasificación: 
TABLA 1

Clases de sanciones ${ }^{[11]}$

\begin{tabular}{|c|c|c|c|}
\hline $\begin{array}{l}\text { Clase de } \\
\text { sanción }\end{array}$ & Duración & Modelo punitivo & Supuesto de hecho \\
\hline Ordinarias & $\begin{array}{l}\text { Entre } 15 \text { y } 20 \\
\text { años de cárcel }\end{array}$ & $\begin{array}{l}\text { Proporcionalista Fines }{ }^{[12]} \text {. } \\
\text { Mayormente retributivo y } \\
\text { resocializador }\end{array}$ & $\begin{array}{l}\text { Sujetos que no } \\
\text { aceptan } \\
\text { responsabilidad y } \\
\text { son vencidos en } \\
\text { juicio }\end{array}$ \\
\hline Alternativas & $\begin{array}{l}\text { Entre } 5 \text { y } 8 \\
\text { años de cárcel }\end{array}$ & $\begin{array}{l}\text { Proporcionalista Fines: } \\
\text { Retributivo moderado }\end{array}$ & $\begin{array}{l}\text { Sujetos que } \\
\text { reconocen la } \\
\text { verdad ante la } \\
\text { Sección de } \\
\text { enjuiciamiento, } \\
\text { antes de expedida } \\
\text { la sentencia. }\end{array}$ \\
\hline Propias & $\begin{array}{l}\text { Entre } 5 \text { a } 8 \\
\text { años de } \\
\text { restricción } \\
\text { efectiva de la } \\
\text { libertad para la } \\
\text { realización de } \\
\text { labores } \\
\text { restauradoras }\end{array}$ & $\begin{array}{l}\text { Mixto } \\
\text { (Proporcionalista-Reparador) } \\
\text { Fines: Retributivo dúctil }\end{array}$ & $\begin{array}{l}\text { Sujetos que } \\
\text { reconocen la } \\
\text { verdad y su } \\
\text { responsabilidad } \\
\text { oportunamente }\end{array}$ \\
\hline
\end{tabular}

Fuente: elaboración propia con base en el Punto 60 del Acuerdo, art. 13 transitorio del Acto Legislativo 01 de 2017, arts. 126, 128, 130, 141, 142 y 143 de la LE-JEP y la sentencia C-080/18

Adicionalmente, el artículo 129 de la LE-JEP establece que tanto las sanciones propias como las alternativas pueden tener una duración entre 2 y 5 años, para quienes no hayan tenido una participación determinante en las conductas más graves y representativas; aun interviniendo en ellas, salvo que se trate de delitos como: de lesa humanidad, genocidio, crímenes de guerra, toma de rehenes u otra privación grave de la libertad, tortura, ejecuciones extrajudiciales, desaparición forzada, acceso carnal violento y otras formas de violencia sexual, sustracción de menores, desplazamiento forzado, además del reclutamiento de menores, de conformidad con lo establecido en el Estatuto de Roma (artículo 23 de la Ley 1820 de 2016) ${ }^{[13]}$. Según el inciso segundo del art. 130 de la LE-JEP, cuando este monto corresponda a una sanción alternativa, deberá cumplirse en un establecimiento penitenciario ordinario ${ }^{[14]}$.

Se advierte desde ahora que los términos pena y sanción corresponden a la consecuencia jurídica por la comisión de un delito y que su diferencia fundamental radica en la órbita de aplicación [Justicia ordinariaJurisdicción Especial para la Paz (en lo sucesivo JEP) $]^{[15]}$ y los fines que deben cumplir ${ }^{[16]}$. No obstante, para Elena Larrauri, existen tres diferencias fundamentales entre pena y sanción ${ }^{[17]}$ : (i) una sanción castiga una infracción administrativa la cual no necesariamente es un delito; (ii) para su imposición no se requiere un juez; y (iii) la sanción no puede ser privativa de la libertad. Esta diferenciación no es aplicable al contexto estudiado ya que las sanciones propias (i) van a castigar infracciones penales (no administrativas); (ii) serán impuestas por un juez (JEP); y (iii) aunque no se va traducir en una privación de la libertad tradicional, sí implicará la restricción de este derecho en un ambiente diferente al penitenciario y carcelario que, en el caso de las sanciones alternativas y ordinarias, coincidirá con este último.

En consecuencia, para el ámbito local y dentro de la coyuntura de esta investigación, las diferencias entre pena y sanción, además de la anotada sobre el juez competente, estarán radicadas en (i) la temporalidad (reducida como consecuencia del contexto transicional) y (iii) la espacialidad (lugar de cumplimiento diferente a la cárcel ${ }^{[18]}$-cuando se trate de sanciones propias ${ }^{[19]}$-). Congruente con esto último, nos es posible diferenciar entre privación de la libertad y restricción de la libertad, consistiendo la primera en una reclusión 
intramural, mientras que la segunda excluye esta posibilidad tratándose de sanciones propias, aunque existan mecanismos de monitoreo y supervisión que garantizan el cumplimiento de lo ordenado por la JEP (art. 127 LE-JEP) ${ }^{[20]}$.

Conforme lo señalado en la tabla 1, la JEP puede imponer sanciones propias, alternativas y ordinarias. La existencia de sanciones alternativas y ordinarias demuestra que el paradigma restaurativo sobre el cual se fundamenta la JEP, no demanda exclusividad del modelo reparador y que puede combinar alternativas retributivas (moderadas o dúctiles), dentro de un modelo proporcionalista que en ocasiones se conjuga con el primero, pero que, en todo caso, tiene como eje la satisfacción de los derechos de las víctimas para la imposición de la sanción.

Respecto de las sanciones propias, esta jurisdicción cuenta con una posibilidad de innovar con el establecimiento de estas consecuencias jurídicas en virtud de la cláusula abierta del Acuerdo y lo normado en los artículos 64 y 65 de la Ley 1922 de 2018. Dentro de estas sanciones restaurativas se han contemplado las siguientes a nivel general:

- Reconstrucción de infraestructura

- Sustitución de cultivos ilícitos

- Contribución a proyectos de interés para la comunidad

- Desminado

El art. 141 de la LE-JEP hace una relación de trabajos, obras y actividades que se pueden desarrollar como proyectos $^{[21]}$ de las sanciones propias, diferenciando su ejecución en zonas rurales, urbanas, y diferenciando sus labores entre la limpieza y erradicación de restos explosivos de guerra, municiones sin explotar y minas antipersona de las áreas del territorio nacional que hubiesen sido afectadas por estos artefactos.

Esto no es óbice para que en los proyectos y sanciones propias se exploren otras posibilidades, como sería la construcción de obras de interés general (especialmente), proyectos pedagógicos que aprovechen las capacidades de los agresores \#inclusive en términos de memoria histórica\#, proyectos educativos a su favor, etc. En todo caso, el artículo 65 de la Ley 1922 de 2018 advierte que se deben consultar a las víctimas los proyectos de ejecución de trabajos, obras o actividades reparadoras y restaurativas en los casos relacionados con violencia de género, supuesto este último que incluye la violencia sexual.

Se reitera que, para el caso de sanciones ordinarias y alternativas, la aplicación de la pena será congruente con el modelo intramural tradicional, sin que exista derecho a subrogados penales, beneficios adicionales o rebajas complementarias a la sanción alternativa (art. 142 LE-JEP). Sin embargo, esto sí aplicará para las sanciones ordinarias cuando se realicen programas de resocialización (art. 143 LE-JEP), conforme a los criterios de redención de la pena.

\section{Fines de la privación y de la restricción de la libertad}

Una pregunta inevitable que surge al abordar la lectura de esta sección sobre un tema que tiene una literatura enorme ${ }^{[22]}$ es: ¿otra vez sobre los fines de la pena? La respuesta está inspirada en algo que se indicó anteriormente y que radica fundamentalmente en el encuadramiento de los fines de la sanción penal dentro del marco transicional colombiano. Aunque otros trabajos contemporáneamente han abordado este problema a partir de la misma temática de manera abstracta ${ }^{[23]}$, la tesis que desarrollaré consiste en afirmar que la consagración de estos fines dentro de un ámbito de justicia ordinaria que culmina con la privación de la libertad, también tiene operatividad en las sanciones de la JEP (tabla 1), pero de una manera flexibilizada. Adicionalmente, se deben tener en cuenta tres objetivos adicionales: (i) paz, (ii) reconciliación y (iii) satisfacción de las víctimas. 
También es importante abordar esta temática ante la consagración dispersa de fines de la pena en el ámbito de la JEP, que no se limita a la regulación del art. 125 de la LE-JEP, sino que menciona la retribución para las sanciones alternativas (art. 128 de la LE-JEP) e incluso a las funciones generales de las normas penales -incluyendo la resocialización- para las sanciones ordinarias (art. 130 de la LE-JEP).

Así, tradicionalmente se han concebido como fines de la pena la retribución, la prevención general y la prevención especial ${ }^{[24]}$. Estos fines se desarrollan a partir de un enfoque ideológico ${ }^{[25]}$ que considera que la pena es una respuesta a la criminalidad y un medio de lucha contra ella ${ }^{[26]}$. Con base en este enfoque se responde a la pregunta: ¿para qué castigar? ${ }^{[27]}$

Las legislaciones penales en la actualidad tienden a usar una miscelánea de estos fines de la pena ${ }^{[28]}$. Algunos piensan que debe ser retributiva, intimidadora e integradora (prevención general) o reeducativa (prevención especial). No obstante, el debate arroja una teoría polifuncional ${ }^{[29]}$, con mayor acento en la reeducación, encontrándose presente siempre la idea de que la pena busca corregir al delincuente y por eso adquiere importancia un modelo rehabilitador dirigido hacia ese fin. A pesar de lo anterior, esta teleología suele quedarse en el discurso ${ }^{[30]}$, ya que los programas de reeducación son insuficientes o poco efectivos.

A continuación, se desarrollarán los distintos fines de la pena: (i) retribución y neoretribución; (ii) prevención general negativa; (iii) prevención general positiva; (iv) prevención especial negativa y (v) prevención especial positiva con miras a adecuarlos tanto en la privación de la libertad (justicia ordinaria), como en la restricción de la libertad (JEP) y las demás sanciones consagradas en este último contexto.

\section{Retribución y neoretribución}

Podemos ubicar la retribución dentro de lo que la literatura jurídico penal denomina teorías absolutas al concebir la pena como un fin en sí mismo ${ }^{[31]}$, al justificar el castigo por su valor axiológico intrínseco, desvinculado del efecto social que este pueda producir. Esta teoría se nutre de los postulados ideológicos de Hegel y Kant ${ }^{[32]}$, este último considera la ley penal como imperativo categórico que conlleva a la aplicación de la pena, mientras que el primero interpreta el delito como negación del derecho y la pena como negación de esta negación ${ }^{[33]}$. La aplicación de la pena se inspira en la lex talionis, sustituida por la equivalencia entre el delito y la pena, en donde esta última se corresponde con la magnitud de la culpabilidad y el daño ocasionado.

Importante advertir que dentro de los postulados clásicos de esta teoría la víctima no ocupa ningún papel y la imposición de la pena no es un derecho para ella $^{[34]}$. En este postulado también se omite que la respuesta punitiva debe tener como base la trasgresión al derecho de una víctima (colectiva o individual), y cede la administración del castigo al Estado, sin que ello implique renuncia de su interés sobre el conflicto y los resultados de su judicialización.

Actualmente, esta teoría ha sido reformulada a partir del proporcionalismo, dentro de una proposición que se conoce como neoretribución o teorías del merecimiento ${ }^{[35]}$. Esta teoría conjuga los principios de lesividad, culpabilidad y proporcionalidad $^{[36]}$ y su respuesta punitiva es una fusión entre censura y sufrimiento ${ }^{[37]}$. La censura se ve reflejada con la adopción de una sentencia condenatoria por parte del juez y en contra del agresor; mientras que el sufrimiento es la consecuencia del daño causado representado en una pena, sin que esta se traduzca necesariamente en la privación de la libertad. Con base en el principio de proporcionalidad, sumado al principio de humanidad, la teoría del merecimiento rechaza los criterios retribucionistas clásicos, inspirados en la lex talionis ${ }^{[38]}$. De esta manera, deja reservada la prisión para los delitos graves ${ }^{[39]}$ : Homicidio (5 años como máximo) y delitos de cuello blanco junto con otros delitos en los que medie la violencia (3 años como máximo) ${ }^{[40]}$.

Dejando a un lado el debate sobre proporcionalidad de las penas, el C.P. permite retribuir el mal causado con el delito a través de la imposición de una pena, que, como anotamos con anterioridad, 
preponderantemente consiste en la privación de la libertad del agresor. Así, frente a la actualización del precepto con base en la acción u omisión del sujeto activo de la conducta, la consecuencia jurídica implicará la reclusión por un período de tiempo significativo, que, salvo algunas excepciones, es susceptible de subrogación $^{[41]}$.

Ahora bien, tanto el Acuerdo como las normas jurídicas que lo han implementado no son ajenos a esta temática, lo que obedece a que, si bien se postulan concesiones que modifican la administración tradicional del castigo -especialmente cuando se aporta verdad y se reconoce responsabilidad oportunamente-, también se aplica cierta dosis de retribución que es justificada por el daño causado. Así, incluso al analizar las sanciones propias, la restricción de la libertad por un período determinado para la realización de proyectos restaurativos se adscribe a la teleología retribucionista ${ }^{[42]}$, que no necesariamente debe confundirse con cárcel.

Adicionalmente, tratándose de las sanciones alternativas y ordinarias, de conformidad con lo dispuesto en el numeral [en lo sucesivo núm.] 60 del punto 5.1.2. del Acuerdo \#referido por el art. 13 transitorio del Acto Legislativo 01 de 2017\# el lapso de privación de la libertad obedece a una teleología retributiva y tratándose de sanciones ordinarias buscan incluso la resocialización. Sin embargo, también en estos supuestos, debe tenerse en cuenta un contenido restaurativo de conformidad con el inciso $4 .^{\circ}$ del art. transitorio 1 y el art. transitorio 13 del Acto Legislativo 01 de 2017 (Sentencia C-080/18).

\section{Prevención general negativa o intimidación}

Las teorías de la prevención general no actúan sobre los individuos, sino sobre la colectividad ${ }^{[43]}$. A su vez, la prevención general negativa gira alrededor de a una amenaza, de la cual se espera conseguir un objetivo en particular: disuasión ${ }^{[44]}$. Así, desde una visión utilitarista, la cárcel es un lugar donde se priva de la libertad a las personas que han infringido la ley, con el objetivo de prevenir delitos y contener a los otros con el terror del ejemplo ${ }^{[45]}$.

Dentro de este ámbito de acción, para que las penas cumplan con su función de prevención, deben imponerse con celeridad ${ }^{[46]}$; es decir que el Estado debe responder prontamente en el ejercicio del ius puniendi. También deben ser certeras ${ }^{[47]}$. Esto, atiende a que no basta su consagración si no se pone en marcha todo un andamiaje que permita la captura y judicialización de los delincuentes ${ }^{[48]}$. Finalmente, deben ser severas ${ }^{[49]}$. Esta severidad no debe superar el umbral necesario para generar disuasión por parte de la colectividad, razón por la cual no debe acudirse al argumento punitivo como única alternativa político criminal, sin la confluencia de los demás factores, que en su ausencia deslegitiman la aplicación de la pena.

\section{Prevención general positiva o integración}

La prevención general positiva busca la estabilización de la norma. Tiene tres efectos fundamentales ${ }^{[50]}$ : (i) aprendizaje: la norma tiene una motivación socio-pedagógica dirigida a la colectividad, emitiendo un mensaje de que se ha realizado un acto prohibido; (ii) confianza: relacionado con la sensación de la sociedad frente a la aplicación de la ley en contra del infractor; y (iii) pacificación: consiste en la tranquilidad de la conciencia colectiva. Con base en esta teoría, la ciudadanía en general percibe la ejecución de la norma penal, reafirmando su validez y eficacia.

Una reformulación de esta postura, con base en la teoría lubmanniana, es la que expone Jakobs en su prevención general positiva como integración social, sumando a la idea de la estabilización del sistema social, la orientación de la acción y la institucionalización de las expectativas ${ }^{[51]}$, al ser la pena un factor de cohesión del sistema político-social ${ }^{[52]}$. Para Jakobs, la pena tiene por destinatarios a todos los miembros de la sociedad \# en cuanto potenciales víctimas\#, para reafirmarlas en la vigencia de la norma jurídica ${ }^{[33]}$. De esta manera, los 
principales requisitos de esta teoría son: (i) vigencia de la norma y (ii) fidelidad hacia el derecho; en cuanto a lo demás, las características se mantienen estables conforme a lo anteriormente expuesto.

Confrontando las variantes de prevención general con el Acuerdo, es necesario preguntarse si es necesario prevenir y si el modelo de sanciones de la JEP genera ese efecto. Para abordar este cuestionamiento compuesto, es preciso señalar de entrada que el conflicto armado en Colombia no ha acabado. Nos encontramos en una fase muy frágil de posacuerdo, en la que la confianza de los actores es reducida y podría conllevar al restablecimiento del conflicto. Adicionalmente, el país lamentablemente mantiene un conflicto armado con otros actores como el Ejército de Liberación Nacional (ELN). Todo esto demuestra la necesidad de continuar previniendo, tanto bajo modelos de intimidación como de integración, aun cuando la primera se encuentre flexibilizada con base en los parámetros del Acuerdo.

Aunque las sanciones de la JEP solo operan para conductas cometidas con anterioridad al $1^{\circ}$ de diciembre de 2016, en principio, no previenen la comisión de delitos cometidos con posteridad, ante lo cual la prevención general negativa estará contenida en el C.P. En todo caso, se vislumbra el precedente de que en todos los casos se establecen sanciones. Incluso se creó una jurisdicción especial para el juzgamiento de esos comportamientos, aun cuando se cometan bajo un fin altruista como justificación teleológica, lo cual no habilita la impunidad. Además, la imposición de las sanciones por parte de la JEP reafirmará la vigencia del ordenamiento jurídico punitivo y la confianza jurídica respecto del mismo en la comunidad en general.

Finalmente, así como en los juicios de Núremberg se identificaron ideas de prevención general ${ }^{[54]}$, en el caso colombiano no solo se debe prevenir la conformación de guerrillas, sino también que las que actualmente están operando dejen de delinquir e incluso -insisto- que las FARC no vuelvan a hacerlo frente a una posible desconfianza ante los devenires de la implementación del Acuerdo.

\section{Prevención especial negativa o incapacitación}

Tanto la prevención especial negativa como la positiva buscan hacer desistir al autor de futuros delitos ${ }^{[55]}$, es decir que se abstiene de comunicar a la sociedad cualquier mensaje, como lo hacen las teorías de la prevención general y se centra exclusivamente en el individuo. La prevención especial positiva y negativa se diferencian por las técnicas a través de las cuales se procura la consecución de este fin. Mientras que la prevención especial negativa incapacita al individuo ${ }^{[56]}$, usando de manera preferente la pena privativa de la libertad, la prevención especial positiva tiende hacia la corrección del mismo, no necesariamente privándolo de su derecho de locomoción.

En este sentido, para la prevención especial negativa basta con la inocuización del sujeto, quien encontrándose privado de la libertad no volverá a cometer delitos, sin tener en cuenta su futuro en libertad y omitiendo las variables que apuntan a la delincuencia intramural, con efectos que no salen de la órbita de control carcelario y otros que traspasan esos muros.

\section{Prevención especial positiva o corrección}

La prevención especial positiva busca la reeducación y la recuperación moral del condenado ${ }^{[57]}$. A partir de esta se pretende reformar al delincuente, con base en programas que suplan las falencias que lo llevaron hacia el camino del delito. Así, se busca fortalecer los valores ético-sociales elementales frente a las acciones que lesionan bienes y se dirigen contra esos valores ${ }^{[58]}$.

Ahora bien, en un contexto de justicia transicional también se busca la corrección ${ }^{[59]}$ que traspasa al agresor como objetivo y se enfoca en la sociedad. Con base en esto, Teitel propone una conjunción entre prevención especial y prevención general positivas ${ }^{[60]}$, que no solo permita que el agresor acepte y reconozca la existencia 
de un ordenamiento legal que lo obliga a actuar de conformidad, sino que, adicionalmente, favorezca a la comunidad en general con la reparación del daño causado y le ofrezca confianza sobre la eficacia del aparato de administración judicial.

En torno a las variantes de la prevención especial, se observa igualmente que las sanciones de la JEP se pueden adecuar con los objetivos perseguidos, no solo porqué en las sanciones ordinarias explícitamente se busca la resocialización de los condenados, sino que incluso en las sanciones propias, la existencia de programas restaurativos logra una corrección del comportamiento del agresor y, adicionalmente, le restringe (sanciones propias) o priva (sanciones alternativas y ordinarias) su derecho a la libertad, en procura de inocuizarlo, con la crítica anteriormente mencionada en este sentido sobre la operatividad de este objetivo en el contexto latinoamericano (ver nota 56).

Empero, los fines de la pena en un contexto de justicia transicional tienen ingredientes adicionales que se enfocan más hacia la paz, la reconciliación y la satisfacción de las víctimas. Así lo reconoce el art. 125 de la LEJEP \# en concordancia con lo establecido en el art. transitorio 13 del Acto Legislativo 01 de 2017\#, y aunque no señala la reconciliación ${ }^{[61]}$ expresamente, considero que esta última es la bisagra necesaria entre las otras dos finalidades expuestas, ya que sin su existencia es imposible conseguir la reconciliación o la satisfacción de las víctimas.

\section{La paz}

El art. 22 Constitucional establece la paz como un derecho y un deber ${ }^{[62]}$, convirtiéndose en un eje identitario de la Constitución ${ }^{[63]}$. La paz implica la ausencia de conflictos o la humanización de los mismos, respetandolas reglas del derecho internacional humanitario. Dentro de un escenario democrático, la paz permite garantizar el goce de los derechos humanos sin que ostente la calidad de valor absoluto ${ }^{[64]}$.

Como consecuencia de la firma del Acuerdo y la búsqueda de la paz, la imposición de las sanciones no cumple la misma estructura que en la justicia ordinaria, ya que se debe garantizar el no retorno al conflicto, bajo una dinámica que sea aceptable para los actores del mismo.

\section{La reconciliación}

Así como fue necesario flexibilizar las penas con miras a suscribir el Acuerdo para satisfacer las pretensiones de los victimarios, es necesario satisfacer las pretensiones de las víctimas. Entre esos dos objetivos se encuentra la reconciliación. Ambos mencionan que la Comisión de la verdad y reconciliación de Sudáfrica buscó la reconciliación de la sociedad, haciendo un trueque entre la punición de los comportamientos por la obtención de verdad, atado al arrepentimiento de los transgresores y el perdón de sus víctimas ${ }^{[65]}$. El Acuerdo sigue una teleología similar que conjuga las pretensiones de las partes y la comunidad en general.

Reyes, en varios apartes de su investigación, hace alusión a la reconciliación en los procesos de justicia transiciona ${ }^{[66]}$. Aunque no la rótula como fin de la pena, al final del documento es enfático en exaltarla como un objetivo indispensable en los procesos de justicia transicional:

La reconciliación supone que los infractores de la ley serán reconocidos como tales, que sean objeto de reproche por esa circunstancia y que ofrezcan una garantía de que jamás repetirán hechos como los que llevaron a su declaración de responsabilidad; pero también implica que las víctimas sean reconocidas como tales, que sean reparadas, que se les garantice el derecho a la verdad y que reciban garantías razonables (ellas y la comunidad en general) de que las conductas delictivas cometidas en desarrollo del conflicto no volverán a repetirse; esto último no solo implica que las partes en conflicto se comprometan a no repetir los actos de violencia ocurridos en desarrollo del mismo, sino que de parte del Estado impone el deber de introducir los correctivos que sean necesarios en los ámbitos social, político y económico para superar las causas 
que dieron origen o permitieron el desarrollo del conflicto; y finalmente, la reconciliación supone que la sociedad acepte esas consecuencias como suficientes para emprender en el futuro una vida social en armonía ${ }^{[67]}$.

En sentido similar, en la sentencia C-007/18 se expresa:

(...) La reconciliación es condición de subsistencia del Estado y presupuesto para que las partes antes enfrentadas ahora se reconozcan mutuamente como actores válidos en la deliberación democrática y la construcción de la razón pública ${ }^{[68]}$. Ha añadido, en tal dirección, que la democracia sólo es viable en el marco de la convivencia pacífica ${ }^{[69]}$, y ha sostenido que la reconciliación es esencial para la reconstrucción de los lazos sociales rotos y para la vigencia de los derechos humanos ${ }^{[70]}$.

Consideramos que esos parámetros permiten concretar la reconciliación, ya que no se enfocan en una parte u otra, sino que involucran a toda la sociedad y al Estado como garante de la paz, teniendo la obligación de realizar los correctivos necesarios para que unos y otros se encuentren satisfechos.

\section{La satisfacción de las víctimas}

Se debe advertir de entrada que la satisfacción de las víctimas como fin de la pena no debe confundirse con el protagonismo de aquellas bajo criterios populistas punitivos ${ }^{[71]}$. Superado lo anterior y acorde con lo establecido en el punto 5 del Acuerdo, es imprescindible que las víctimas se sitúen en el centro del sistema de administración de justicia para la paz.

Así, la imposición de la sanción es un acto de comunicación a través del cual se les reconoce a las víctimas la calidad de afectadas ${ }^{[72]}$ y concreta los postulados de la prevención general positiva, ya no en cabeza de la colectividad sino de aquellas. Es decir, que emite el mensaje de que se realizó un comportamiento prohibido, les otorga una sensación de confianza frente a la aplicación de la ley en contra del infractor y le brinda tranquilidad, no solo por concretarse la justicia y la reparación, sino también por las garantías de no repetición exigibles en un contexto transicional.

Este será uno de los grandes retos de la JEP, permitirle no solo un derecho a voz como tradicionalmente ha ocurrido con las víctimas en la tramitación de los procesos penales, sino también un poder de decisión y una participación activa que, aunque resulte monumental en ocasiones, debe ser congruente con los principios rectores de este procedimiento y los lineamientos del Acuerdo.

\section{Modelos punitivos ¿Hacia un paradigma restaurativo en la JEP?}

Con base en los fines ideológicos de la pena y los términos clave sobre los cuales ha girado en el tiempo ${ }^{[73]}$ : reforma moral, adiestramiento, tratamiento, corrección, rehabilitación, disuasión e incapacitación; en la actualidad suelen diferenciarse 4 modelos punitivos ${ }^{[7]}$ para la imposición de la misma: (i) proporcionalista, (ii) rehabilitador, (iii) reparador/restaurador e (iv) incapacitador/inocuizador. Con la exposición de los mismos se pretende dar respuesta a las preguntas: ¿por qué se castiga con la pena de prisión? ${ }^{[75]}$, y ¿qué otras alternativas existen para concretar los fines de la pena? Una reformulación de la anterior pregunta para el contexto transicional colombiano sería: ¿ ¿por qué se castiga con la sanción penal?

De estos modelos, el que privilegia la pena privativa de la libertad es el incapacitador, mientras que los modelos rehabilitador y reparador se apartan de esa asociación directa y automática entre delito y cárcel, bajo la dinámica causa y efecto. Por su parte el proporcionalista, como se había anticipado con anterioridad, deja reservada la pena de prisión para los delitos graves, mientras que para los otros delitos menos graves o leves podrán aplicarse penas alternativas, dentro de las cuales pueden considerarse adecuadas las multas o el trabajo en beneficio de la comunidad. 


\section{Modelo proporcionalista}

Con base en la teoría de Wasik y Von Hirsch ${ }^{[76]}$ se desarrolla este modelo, donde la gravedad del delito es el eje central sobre el cual gira su aplicación. Se propone una escala de castigos que asocie la gravedad de los mismos con la gravedad del delito: delito grave-castigo grave, delito leve-castigo leve ${ }^{[77]}$.

Se advierte nuevamente que no es la pena de prisión la única alternativa para reprimir el comportamiento del delincuente. Con base en criterios de proporcionalidad podrían imponerse penas pecuniarias o penas alternativas a la prisión como el trabajo en beneficio de la comunidad, fuertemente implementado en España e inspirado en el mandato constitucional (artículo 25-2) de reeducación y reinserción social respecto de las penas, que adquiere gran importancia en el desarrollo del modelo rehabilitador ${ }^{[78]}$.

\section{Modelo rehabilitador}

Este modelo excluye la prisión como primera opción ${ }^{[79]}$, atendiendo a que privilegia la resocialización del individuo, lo cual ocurre de mejor manera en libertad, dejando aquella reservada a la imposibilidad de realizar el tratamiento rehabilitador sin el internamiento. Así, busca que el individuo no vuelva a delinquir en el futuro, atacando los factores específicos que vinculan al sujeto con la comisión de delitos ${ }^{[80]}$.

En este punto es preciso señalar que el trabajo es un instrumento muy importante para la resocialización ${ }^{[81]}$. No solo por su potencialidad moralizadora, sino por la posibilidad implícita de que, a través del conocimiento de un oficio intramuros, este se pueda realizar en libertad, procurando la subsistencia del condenado y evitando que se cometan delitos como consecuencia directa.

\section{Modelo incapacitador}

El objetivo de este modelo es neutralizar al victimario e impedir que delinca durante el tiempo que se encuentre privado de la libertad. Teniendo en cuenta la distribución de los recursos escasos, este modelo no utiliza la prisión de manera generalizada, sino que la deja reservada para las personas que presenten mayor riesgo de reincidencia en el delito ${ }^{[82]}$.

Con base en esta teoría y los criterios de incapacitación selectiva que implican no enviar a la cárcel a todos los agresores de la ley penal bajo un análisis de costo-beneficio, se edifica la conocida teoría americana de los three strikes and you are out ${ }^{[83]}$ que, siguiendo la metáfora con el juego de baseball, ofrece tres oportunidades al delincuente para evitar la prisión, al cabo de las cuales, es internado a perpetuidad. Lo anterior como consecuencia de su imposibilidad de corrección, siendo estos lo más peligrosos y/o persistentes ${ }^{[84]}$.

\section{Modelo reparador/restaurativo}

Tomando como referente la obra de Braithwaite ${ }^{[85]}$, el modelo reparador o restaurativo se enfoca en la víctima. Pretende la reparación del daño y la paz social. Para lograr estos objetivos, las partes afectadas con el conflicto se ponen en contacto y solucionan la controversia, quedando reservada la prisión a los eventos en que la justicia reparadora no logre sus objetivos ${ }^{[86]}$. Este modelo consagra como uno de sus instrumentos la vergüenza reintegrativa ${ }^{[87]}$, que se acerca a la infamia pregonada por Foucault ${ }^{[88]}$, utilizando la opinión pública para castigar los delitos, sin acudir al uso universal de la prisión.

En el marco de este modelo se encuadra la justicia restaurativa como una forma de administrar una sanción que intenta responder a las necesidades y limitaciones que enfrenta la justicia en la actualidad ${ }^{[89]}$. Igualmente, 
procura devolver el conflicto a las partes para que ellas directamente lleguen a una solución, habilitando la participación de otros interesados, con miras a recomponer el tejido social afectado con el delito.

Empero, este modelo de justicia se nutre de la solución de los conflictos por parte de las comunidades aborígenes (ancestrales), con prácticas que incluyen la participación de la comunidad y privilegian la reparación de la víctima, contrario sensu a lo que ocurre con la justicia retributiva que termina silenciando sus pretensiones y se preocupa más por el interés estatal.

Una de las prácticas restaurativas con mayor desarrollo contemporáneo es la mediación, que no solo permite concretar la participación de las víctimas, sino también concretar los fines de prevención especial y prevención general. Al respecto advierte Sampedro:

Desde el punto de vista de la prevención especial, con la mediación se procura enfrentar al victimario-delincuente con la realidad de las víctimas, con el delito cometido y las consecuencias sociales que se derivan del mismo, lo cual fomenta una conciencia de responsabilidad por sus propios actos y genera una actitud que favorece el compromiso en la realización de actuaciones concretas a favor de las víctimas.

(...)

En cuanto a la prevención general positiva, hoy de enorme relevancia en el derecho penal, la mediación puede lograr el afianzamiento de la confianza ciudadana en la imposición del derecho penal, así como la satisfacción de observar cómo se superan los efectos del delito y se genera un efecto pacificador de las relaciones sociales, que puede proyectarse en el resto de la sociedad (Prevención integradora). ${ }^{[90]}$

Insisto, no solo la pena de prisión logra concretar los fines ideológicos de la pena. Se puede recurrir a otras alternativas que, en todo caso, no tienen que ser exclusivas, satanizando uno u otro modelo. Es decir, el hecho de que se aplique un modelo reparador no prescinde de cierta dosis de privación de la libertad ni la aplicación de esta última por fuera del modelo tradicional de la cárcel, como lo demuestran las sanciones alternativas y ordinarias de la JEP. Adicionalmente, y dependiendo tanto del perfil del agresor de la ley penal como de las pretensiones de la víctima, puede que la cárcel resulte insuficiente y existan otras medidas más idóneas para resolver la controversia objeto de la comisión de un delito, dentro lo cual puede funcionar bien el modelo de sanciones propias de la JEP.

Retornando a la tabla 1, podemos observar que, aunque el Acuerdo retóricamente se enmarca dentro de un modelo reparador, sigue adecuándose a un modelo proporcionalista que incluye fines preventivos y retribucionistas y que, en el caso de las sanciones propias, permite pregonar una mixtura de modelos (proporcionalista-reparador) respecto de la consecuencia jurídica por los delitos cometidos, es decir, respecto de la sanción propia.

Aunque el punto 5 del Acuerdo y las reglas de procedimiento de la JEP invitan a considerar la

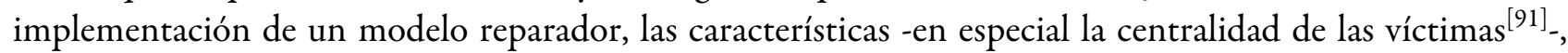
no se ven reflejadas en la incipiente intervención que regulan las normas de implementación ${ }^{[92]}$, que en definitiva deja reservada la intervención de las víctimas para la última etapa de resolución del conflicto: la imposición de la sanción. Rescatando la ruptura entre sanción penal y cárcel y la reparación que se busca con la primera a favor de las víctimas, podemos evidenciar un viraje hacia un paradigma restaurativo, que exige mayor posicionamiento y desarrollo.

\section{Dosimetría punitiva (justicia ordinaria y justicia transicional)}

Una vez descritas las sanciones-penas, los fines que se persiguen con las mismas y los modelos punitivos en los que se encuadra de mejor manera la consecuencia jurídica por la trasgresión de la norma penal, ora en sede ordinaria (proporcionalista), ya en sede transicional (proporcionalista y reparador), es importante analizar la manera como se dosifican las penas en ambos contextos. 
El CP contiene un sofisticado sistema de dosificación punitiva que exige la motivación de la pena (art. 59), con base en el sistema de cuartos ${ }^{[93]}$, que implica determinar los mínimos y máximos punitivos con base en las reglas del art. 60, ante la existencia de circunstancias que la modifiquen; como por ejemplo las circunstancias de atenuación o agravación que disminuyen o aumentan las penas en determinadas proporciones. Para obtener el ámbito punitivo de movilidad se resta el mínimo al máximo y ese resultado se divide en cuatro, obteniendo un cuarto mínimo, dos cuartos medios y un cuarto máximo. La ubicación en estos cuartos dependerá de la existencia de circunstancias de menor (art. 55) y/o mayor punibilidad (art. 58), que también operan para nuestro escenario transicional.

Una vez seleccionado el cuarto correspondiente, el juzgador tendrá en cuenta las siguientes circunstancias para tasar la pena: (i) mayor o menor gravedad de la conducta; (ii) daño real o potencial creado; (iii) naturaleza de las causales que agraven o atenúen la punibilidad; (iv) la intensidad del dolo; (v) la preterintención o la culpa concurrentes; (vi) la necesidad de pena; y (viii) la función que ella ha de cumplir en el caso concreto (art. 61) ${ }^{[94]}$.

La dosificación de la pena en la JEP no aplica el sistema de cuartos. Los arts. 64 de la Ley 1922 de 2018 y 136 de la LE-JEP amplían el margen de discrecionalidad de los funcionarios judiciales para establecer las penas, respetado los baremos punitivos establecidos para las diferentes sanciones (tabla 1), teniendo en cuenta: (i) el grado de verdad otorgado por la persona y la prontitud con la que se haya hecho; (ii) la gravedad y modalidades de la conducta sancionada; (iii) el nivel de participación y responsabilidad, las circunstancias de mayor y menor punibilidad; (iv) los compromisos en materia de reparación a las víctimas y garantías de no repetición y (v) la personalidad del agente.

Cuando se trate de concurso, adicionalmente se tienen en cuenta (vi) el número de conductas punibles, (vii) la magnitud del daño causado, en particular a las víctimas y familiares; (viii) los medios empleados para cometer la conducta; (ix) el grado de intencionalidad; (x) las circunstancias de modo, tiempo y lugar; (xi) la especial vulnerabilidad de las víctimas; (xi) el grado de instrucción y condición social del acusado.

Existen dos puntos importantes para resaltar de lo anterior. Primero, aunque las normas de dosificación punitiva para la JEP no tienen consagrada la función que la sanción debe cumplir, el art. 125 de la LEJEP regula la finalidad de estas, como criterio orientador de este proceso. Adicionalmente, se reitera la reparación de las víctimas como fundamento para la individualización de la sanción. Segundo, para las sanciones alternativas se exige el cumplimiento de un fin esencialmente retributivo (art. 128 de la LE-JEP) y para las sanciones ordinarias se incluye el fin resocializador, que debe tener en cuenta la personalidad del agente. Respecto de estas últimas, la regulación remite a las funciones de las normas penales (art. 130 de la LE-JEP), es decir, las consagradas en el art. 4 del C.P., que deberán ser tenidas en cuenta por el juzgador al momento de decidir la pena imponible.

A continuación, y con base en un caso hipotético sobre homicidio en persona protegida, procederemos a verificar el proceso de dosimetría penal en los dos escenarios que hemos venido comparando a lo largo de este artículo. Como punto de partida, se debe tener en cuenta el art. 135 del C.P. que circunscribe el supuesto de hecho aplicable a ambos contextos. La consecuencia jurídica consagrada en esa norma solo será aplicable en el contexto de la justicia ordinaria, mientras que en el ámbito de la JEP se tendrá en cuenta la tabla 1.

Por otra parte, no se aplicará lo dispuesto en el artículo 129 de la LE-JEP por cuanto el delito atribuido tiene la calidad de crimen de guerra (art. $8 .^{\circ}$ del Estatuto de Roma).

\section{CASO HIPOTÉTICO}

Con ocasión del conflicto armado, el día 20 de noviembre de 2000, A (de extracción campesina, sin contar con ninguna condena en su contra y que se convirtió en el mejor francotirador de la FARC-EP), mató a Y (adolescente de 17 años de edad, integrante de la población civil) en inmediaciones de la población X donde se desarrollaba una confrontación bélica entre ese grupo armado al margen de la ley y el Ejército Nacional de Colombia. Para lograr su cometido, A contó con la colaboración de $\mathrm{B}$ y C, el primero encargado de medir la distancia hacia el objetivo y el segundo de medir el viento para lograr un disparo certero. 
En procura de reparar a las víctimas, A vendió la motocicleta de su propiedad y entregó el dinero de la venta a los padres de A, ofreciendo excusas por su comportamiento y explicando que mató a Y por ser la novia de W (capitán del Ejército). Los padres de Y no perdonaron a A y esperan que se "pudra en la cárcel”.

* La última parte del caso (reparación, perdón y verdad) no aplica para la dosimetría de la sanción ordinaria de la JEP

\section{Dosimetría punitiva en la justicia ordinaria (modelo proporcionalista)}

Como se explicó con anterioridad, para la individualización de la pena en este contexto se deberá utilizar el sistema de cuartos. La Fiscalía General de la Nación imputó y acusó a A por el delito de homicidio en persona protegida con circunstancia de mayor punibilidad [obrar en coparticipación criminal (art. 59-10 C.P.)]. Comoquiera que no se imputaron circunstancias de atenuación o agravación punitiva, el máximo de la pena corresponde a 360 meses y el mínimo a 240 meses. La diferencia entre los extremos es de 120 meses que divididos en 4 nos arroja una proporción de 30 meses (tabla 2).

TABLA 2

Dosificación punitiva del homicidio en persona protegida - Justicia ordinaria

\begin{tabular}{lll}
\hline Cuarto mínimo & Cuartos medios & Cuarto máximo \\
\hline 240 a 270 meses & 270 meses y un día a 330 meses & 330 meses y un día a 360 meses \\
\hline
\end{tabular}

Fuente: elaboración propia

Atendiendo a la confluencia de circunstancias de mayor (art. 59, núm. 10, C.P.) y menor punibilidad [carencia de antecedentes (art. 54, núm. 1, C.P.) y reparación/indemnización del daño causado (art. 54, núm. 6, C.P.)], el juzgador deberá ubicarse en los cuartos medios y al valorar los factores del art. 61 del C.P. podrá considerar que la conducta es grave, comoquiera que la víctima era una adolescente de 16 años de edad, con toda una vida por delante. Su muerte no solo cegó su vida, sino que ocasionó un daño que repercute en la ausencia de esa persona en la vida de sus seres queridos.

Adicionalmente, estamos en presencia de un francotirador que tiene conocimientos especiales para impactar a su objetivo, quien, adicionalmente, contaba con una estructura integrada por $\mathrm{B}$ y $\mathrm{C}$, lo que amerita la circunstancia de mayor punibilidad imputada y la ubicación en los cuartos medios.

Lo anterior, junto con los hechos probados, conlleva a demostrar que la intensidad del dolo - que en este caso es de primer grado - es mayor a la exigible frente a otro sujeto pasivo de la conducta (mayor de edad) y un sujeto activo menos capacitado, que, en virtud de su proceder, amerita un fin retributivo de la pena dentro de un modelo proporcionalista y que, por tratarse de una conducta grave, merece una pena grave. Además, la pena en este caso debe enviar un mensaje a la comunidad en el sentido que desincentive la comisión de estos delitos y devuelva la confianza de todo el conglomerado frente a la existencia de justicia. Sin embargo, también debe buscar que el individuo no vuelva a delinquir, incapacitándolo en privación de la libertad por un tiempo proporcional al daño cometido, lapso que deberá aprovechar el Estado para buscar su resocialización. Con base en esta argumentación, la pena a imponer estará muy cerca del máximo establecido en los cuartos medios (330 meses $\left.{ }^{[95]}\right)$.

\section{Dosimetría punitiva en la justicia transicional (modelo proporcionalista-reparador)}

Volviendo a la tabla 1, la dosificación de la pena dependerá del reconocimiento de verdad y responsabilidad, y la oportunidad en que se realice. En virtud de lo anterior, en esta sección se analizará la imposición de sanciones propias, alternativas y ordinarias, dándose por descontado el criterio de gravedad de la conducta expuesto en la justicia ordinaria, que igualmente opera en este contexto. 


\section{Sanciones propias (A aportó verdad y reconoció responsabilidad en la primera oportunidad)}

Aunque se trata de una conducta grave, se otorgó verdad con prontitud y se reparó a las víctimas, lo que amerita la imposición de una sanción propia. La restricción de la libertad de A puede fluctuar entre 5 y 8 años que, con base en los factores consagrados en los arts. 64 de la Ley 1922 de 2018 y 136 de la LE-JEP, favorecen su ubicación en el mínimo. Ahora bien, A era campesino y se convirtió en francotirador de las FARC-EP (con especial precisión respecto del objetivo) lo que en virtud de esta personalidad ameritaría aumentar el mínimo de la pena y fijar una pena aproximada de 6 años de restricción de la libertad (retributivo dúctil), realizando un proyecto restaurativo de limpieza y erradicación de restos explosivos de guerra, municiones sin explotar y minas antipersonales en la zona rural de la población X. En materia pedagógica, se podrían sumar a su proyecto la reconstrucción histórica de lo acontecido junto con el repudio por el uso de las armas y las consecuencias nefastas que el mismo conlleva. Finalmente, se le puede vincular a proyectos de construcción con interés general para la comunidad.

\section{Sanciones alternativas (A aportó verdad y reconoció responsabilidad antes de proferirse sentencia en su contra)}

Siguiendo la argumentación para la sanción propia y excluyendo tanto la posibilidad de restricción de la libertad como el argumento de verdad oportuna; proporcionalmente la pena deberá ser superior a 6 años, sin llegar al máximo punitivo de 8 , por lo que un lapso de 7 años otorga retribución moderada en el caso concreto. En cuanto a las funciones, las sanciones alternativas deberán enviar un mensaje a la sociedad bajo el entendido de que, de cometerse estos delitos, ya no contarán con la prebenda transicional, sino con la represión punitiva ordinaria, aunado a la confianza para todos de la vigencia de la norma. Respecto al agresor de la ley, se le retribuye el mal causado con la privación de la libertad y se le inocuiza para la comisión de delitos. Aunque durante este tiempo puede desarrollar actividades de resocialización, las mismas no se traducirán en redención de pena.

\section{Sanciones ordinarias (A no aportó verdad y no reconoció responsabilidad, siendo acreditada su responsabilidad penal)}

La fundamentación para tasar la sanción ordinaria en el presente caso no se distancia en gran medida de la utilizada en la justicia ordinaria, pero la consecuencia jurídica será diferente, a pesar de que obedece a un grado de retribución superior a los escenarios anteriores.

Atendiendo a la gravedad de la conducta y la falta de contribución a la satisfacción de los derechos de las víctimas como eje central de este sistema, la pena a imponer estará muy cerca del máximo establecido para estas sanciones (20 años), que, en todo caso, resultará más favorable frente a la imponible por la justicia ordinaria (27 años y 6 meses). Esta pena será susceptible de redención con base en las actividades de resocialización que desarrolle el condenado durante el tiempo de privación de la libertad.

El anterior ejercicio demuestra que los fines de la pena y el modelo punitivo son indispensables para establecer el monto de la sanción penal, ya que no será lo mismo buscar restauración que retribución o aplicar la pena dentro de un modelo proporcionalista versus un modelo reparador. 


\section{Conclusión}

La imposición tradicional de la consecuencia jurídica frente a la actualización de la descripción típica, en lo que atañe al supuesto de hecho exigido en la norma penal, resulta insuficiente en un escenario de posacuerdo. La búsqueda de una paz estable y duradera como consecuencia de un acuerdo imposibilita satisfacer la pretensión ortodoxa (más emocional y menos racional) que asocia el delito con la cárcel y exige buscar alternativas como la justicia restaurativa, que se enfoca en las víctimas y la reconstrucción del tejido social, seriamente lesionado tras lustros de conflicto armado interno.

La cárcel no es la única respuesta punitiva con que cuenta el Estado para hacer efectivo el ius puniendi. Las dinámicas de la sanción pueden hacerse efectivas a través de otras clases de penas que, siguiendo la inspiración del siglo de las luces, puedan resultar más humanas y arrojen mejores repercusiones en la persona del condenado, con un impacto favorable extensible a la sociedad.

Adicionalmente, la cárcel ha fracasado como herramienta principal para concretar la resocialización como fin de la pena y las alternativas restaurativas se muestran como una solución óptima para garantizar no solo la reparación, sino también la prevención desde sus órbitas general y especial. Así, la satisfacción de las víctimas como fin de la pena irradia los demás fines perseguidos y, en un contexto de transición, permiten una justicia adecuada dentro de las cesiones inminentes producto de la negociación, con miras a lograr la paz y la reconciliación.

Una restricción de la libertad para realizar labores restauradoras se muestra más provechosa que una privación de la libertad dentro de un contexto carcelario como el colombiano, que no ofrece ningún rédito para nadie. Se suma a esto la reducida probabilidad de captura del agresor penal en un contexto ordinario, las dificultades de obtener una condena y el sometimiento a la sociedad en general de una situación de conflicto que va en contravía de la apuesta constitucional por la paz. En definitiva, el Acuerdo consagra un nuevo paradigma de sanciones penales que no solo responde a la imposibilidad de la justicia ordinaria sino también a desarrollar una alternativa que sane las heridas, con potencial de ser estable y duradera.

\section{Bibliografía}

Alessandro Baratta, Criminología crítica y crítica del derecho penal (Siglo XXI editores, 1989).

Alicia Gil, Sobre la satisfacción de la víctima como fin de la pena, Indret: Revista para el Análisis del Derecho, n. ${ }^{\circ}$ 4, 1-39 (2016). https://www.raco.cat/index.php/InDret/article/view/314492/404645

Álvaro Pérez, Introducción al derecho penal (Temis, 2009).

Andrew von Hirsch, Censurar y Castigar (Elena Larrauri, Madrid trad., Trotta, 1998).

Andrew von Hirsch, Censure and sanctions (Clarendon Press, 1993).

Carmen Ruiz, Lección 2: Teoría de los fines de la pena, en Lecciones de derecho penal. Parte General, 29-42 (2011).

Cesare Beccaria, De los delitos y de las penas (J.A. de las Casas, trad., Alianza, 1982).

Comisión Internacional De Juristas, Colombia: Jurisdicción Especial para la Paz, análisis a un año y medio de su entrada en funcionamiento (junio, 2019).

Corte Constitucional de Colombia, Sentencia C-007 de 2018 (M. P. Diana Fajardo Rivera; 1 de marzo de 2018).

Corte Constitucional de Colombia, Sentencia C-041 de 2017 (M. P. Gabriel Eduardo Mendoza Martelo y Jorge Iván Palacio Palacio; 1 de febrero de 2017).

Corte Constitucional de Colombia, Sentencia C-080 de 2018 (M. P. Antonio José Lizarazo Ocampo; 15 de agosto de 2018).

Corte2602șțtucional de Colombia, Sentencia C-088 de 2002 (M. P. Eduardo Montealegre Lynett; 13 de febrero de 
Corte Constitucional de Colombia, Sentencia C-102 de 2015 (M. P. Gloria Stella Ortiz Delgado; 11 de marzo de 2015).

Corte Constitucional de Colombia, Sentencia C-1080 de 2002 (M. P. Alvaro Tafur Galvis; 5 de diciembre de 2002).

Corte Constitucional de Colombia, Sentencia C-191 de 2016 (M. P. Alejandro Linares Cantillo; 20 de abril de 2016).

Corte Constitucional de Colombia, Sentencia C-232 de 2002 (M. P. Clara Inés Vargas Hernández; 4 de abril de 2002).

Corte Constitucional de Colombia, Sentencia C-259 de 2016 (M. P. Luis Guillermo Guerrero Pérez; 18 de mayo de 2016).

Corte Constitucional de Colombia, Sentencia C-368 de 2014 (M. P. Alberto Rojas Ríos; 11 de junio de 2014).

Corte Constitucional de Colombia, Sentencia C-379 de 2016 (M. P. Luis Ernesto Vargas Silva; 18 de julio de 2016).

Corte Constitucional de Colombia, Sentencia C-392 de 2002 (M. P. Alvaro Tafur Galvis; 22 de mayo de 2002).

Corte Constitucional de Colombia, Sentencia C-434 de 2013 (M. P. Alberto Rojas Ríos; 10 de julio de 2013).

Corte Constitucional de Colombia, Sentencia C-489 de 1996 (M. P. Antonio Barrera Carbonell; 26 de septiembre de 1996).

Corte Constitucional de Colombia, Sentencia C-539 de 2016 (M. P. Luis Ernesto Vargas Silva; 5 de octubre de 2016).

Corte Constitucional de Colombia, Sentencia C-575 de 2009 (M. P. Humberto Antonio Sierra Porto; 26 de agosto de 2009).

Corte Constitucional de Colombia, Sentencia C-577 de 2014 (M. P. Martha Victoria Sáchica Méndez; 6 de agosto de 2014).

Corte Constitucional de Colombia, Sentencia C-579 de 2013 (M. P. Jorge Ignacio Pretelt Chaljub; 28 de agosto de 2013).

Corte Constitucional de Colombia, Sentencia C-652 de 2003 (M. P. Marco Gerardo Monroy Cabra; 5 de agosto de 2003).

Corte Constitucional de Colombia, Sentencia C-689 de 2002 (M. P. Alvaro Tafur Galvis; 27 de agosto de 2002).

Corte Constitucional de Colombia, Sentencia C-764 de 2002 (M. P. Jaime Córdoba Triviño; 17 de septiembre de 2002).

Corte Constitucional de Colombia, Sentencia C-798 de 2008 (M. P. Jaime Córdoba Triviño; 20 de agosto de 2008).

Corte Constitucional, Sentencia C-239 de 2014 (M. P. Mauricio González Cuervo; 9 de abril de 2014).

Corte Suprema de Justicia, Sala de Casación Penal, Sentencia del 20 de septiembre de 2016, Radicado 47588 [SP-133502016], M.P. José Luis Barceló Camacho.

David Garland, Castigo y sociedad moderna. Un estudio de teoría social (Berta Ruiz trad., Siglo XXI Editores, 1999).

David Suarez \& Laura Restrepo, Comparativo de cinco procedimientos administrativos sancionatorios (Fase II): Faltas - Sanciones - Etapas - Segunda Instancia - Principios, . Summa Iuris, n. ${ }^{\circ}$ 2, 224-250 (2016). https://doi.org/1 $0.21501 / 23394536.2327$

Elena Larrauri, Introducción a la criminología y al sistema penal (Trotta, 2015).

Eugenio Zaffaroni, Alejandro Alagia, \& Alejandro Slokar, Derecho Penal. Parte General (Ediar, 2000).

Fernando Velásquez, Manual de derecho penal. Parte general (2010).

Francis Cullen, \& Karen Gilbert, Reaffirming Rehabilition (Anderson Publishing, 1981)

Georg Rusche \& Otto Kirchhmeimer, Pena y estructura social (Emilio Garcia trad., Temis, 1984).

Gloria Gallego, Perdón y proceso de paz en Colombia, 12 Revista Nuevo Foro Penal, n. ${ }^{\circ}$ 87, 159-180 (2016). https:// doi.org/10.17230/nfp.12.87.5

Günther Jakobs, Derecho Penal. Parte General. Fundamentos y Teoría de la Imputación (J. Cuellos y J. Serrano trads., Marcial Pons, 1995).

Howard Zehr, El pequeño libro de la justicia restaurativa (Good Books, 2010). 
I Adolfo Murillo, Justicia transicional y fines de la pena en el contexto colombiano, en Contribuciones al derecho contemporáneo, en Derechos Humanos y Justicia Transicional 149-174 (Diego Tarapués \& Adolfo Murillo coord., 2018).

I Alfonso Reyes, Obras completas (Temis, 1998).

I Claus Roxin, Derecho penal. Parte General. Fundamentos de la estructura de la teoría del delito (Diego Manuel Luzón Peña, Miguel Díaz, et al. trads., Civitas, 1999).

I Iñaki Rivera, La cuestión carcelaria. Historia, Epistemología, Derecho y Política penitenciaria (Editores del Puerto, 2006).

Insigth Crime, El dilema de las prisiones: incubadoras del crimen organizado en Latinoamérica (2017). https://es.insightcrime.org/images/PDFs/2017/El-dilema-de-las-prisiones-incubadoras-del-crimen-or ganizado-en-Latinoamerica.pdf

Jeremías Bentham, El panóptico (La piqueta, 1979).

John Braithwaite, Crime, Shame and Reintegration (Cambridge University Press, 1989). https://doi.org/10.1017/C BO9780511804618

John Braithwaite, Restorative justice and responsive regulation (Oxford University Press, 2002)

Jose Cid, La elección del castigo (Bosch, 2009)

José Cid, Prevención de delitos y utilitarismo: una confusión censurable (a propósito de "censurar y castigar" de A. von Hirsch, Jueces para la democracia, n. ${ }^{\circ} 35,20-27$ (1999). https://dialnet.unirioja.es/servlet/articulo?codigo=17 4792

Juan Bustos, \& Hernan Hormazabal, Nuevo sistema de derecho penal (Trotta, 2004).

Julio Sampedro, Apuntes sobre la resocialización en el sistema penitenciario colombiano, Eguzkilore: Cuaderno del Instituto Vasco de Criminología, n. ${ }^{\circ}$ 12, 107-111 (1998). http://hdl.handle.net/10810/27345

Julio Sampedro, La rehumanización del sistema penal. Una propuesta desde las víctimas y la justicia restaurativa (Pontificia Universidad Javeriana, Equion Energía para la vida, Instituto Berg de Derechos Humanos, Grupo Editorial Ibáñez, 2019).

Jurisdicción Especial para la Paz, Sala de apelación, sentencia interpretativa TP-SA-SENIT 1 de 2019 "Beneficios provisionales, régimen de condicionalidad y participación de victimas" (2019).

Kai Ambos, Sobre los fines de la pena al nivel nacional y supranacional, Revista de Derecho Penal y Criminología, n. 122, 191-211 (2003). http://revistas.uned.es/index.php/RDPC/article/view/24847

Ley 1098 de 2006. Por la cual se expide el Código de la Infancia y la Adolescencia. 9 de noviembre de 2006. D. O. 46.446

Ley 1820 de 2016. Por medio de la cual se dictan disposiciones sobre amnistía, indulto y tratamientos penales especiales y otras disposiciones. 30 de diciembre de 2016. D. O. 50102.

Ley 1922 de 2018. Por medio de la cual se adoptan unas reglas de procedimiento para la Jurisdicción Especial para la Paz. 18 de julio de 2018. D. O. 50.658.

Ley 1957 de 2019. Estatutaria de la Administración de Justicia en la Jurisdicción Especial para la Paz. 6 de junio 2019. D. O. 50.976.

Ley 599 de 2000. Por la cual se expide el Código Penal. 24 de julio de 2000. D. O. 44.097

Ley 65 de 1993. Por la cual se expide el Código Penitenciario y Carcelario. 19 de agosto de 1993. D. O. 40.999.

Ley 890 de 2004. Por la cual se modifica y adiciona el Código Penal. 7 de julio de 2004. D. O. 45.602

Lisa Stolzenberg, \& Stewart J. D’Alessio, "Three Strikes and You're Out": The impact of Californian's new mandatory sentencing law on serious crime rates, 43 Crime \& Delinquency, n. ${ }^{\circ} 4,457-469$ (1997). https://doi.org/10.1177 /0011128797043004004

Lorena Vega, Modelo de justicia transicional: el caso colombiano, en Retos en la implementación de los acuerdos de paz en Colombia,111-130 (Gerardo Ruiz, Ildiko Szegedy y Rafael Prieto eds., 2018).

Luigi Ferrajoli, Derecho y razón. Teoría del garantismo penal (Perfecto Ibañez, Alfonso Ruiz, Juan Carlos Bayón, Juan Terradillos y Rocio Cantarero, trads., Trotta, 2009). 
Luisa Caldas, Aproximación a los problemas fundamentales de la justicia transicional. Especial énfasis en las sanciones imponibles en el marco de la jurisdicción especial para la paz, 37 Derecho Penal y Criminología, n. $102,105-120$ (2016). https://doi.org/10.18601/01210483.v37n102.06

Manuel Cancio, Dogmática y politica criminal en una teoría funcional del delito, en El sistema funcionalista de derecho penal. Ponencias presentadas en el II Curso Internacional de Derecho Penal (Lima, 29, 31 de agosto y 01 de setiembre de 2000), (Günther Jakobs \& Manuel Cancio, Grijley, Lima, 2000).

Martin Wasik, \& Andrew von Hirsch, Non-custodialpenalties and the principles of desert, 32 The Criminal Law Review, 555-572 (1998).

Massimo Pavarini, 'Economía del exceso' y castigos excesivos, Bulletin de la Société internationale de défense sociale pour une politique criminelle humaniste, n. $^{\circ} 30,229-244$ (2003).

Michel Foucault, La sociedad punitiva, en La vida de los hombres infames (La piqueta, 1990).

Michel Foucault, Vigilar y castigar. Nacimiento de la prisión (Siglo XXI Editores, 1976).

Norberto Hernández, El derecho penal de la cárcel. Una mirada al contexto colombiano con base en el giro punitivo y la tendencia al mayor encarcelamiento (Siglo del Hombre Editores, Universidad de los Andes, Universidad EAFIT, 2018).

Norberto Hernández, El discurso protector de las víctimas. Populismo punitivo en España y Colombia, 59 Revista Criminalidad, n. ${ }^{\circ}$ 1, 117-127 (2017). http://www.scielo.org.co/scielo.php?pid=S1794-31082017000100117\& script $=$ sci_abstract\&tlng=es

Norberto Hernández, El fracaso de la resocialización en Colombia, Revista de Derecho, n. ${ }^{\circ} 49,1-41$ (2018). https://d oi.org/10.14482/dere.49.10801

Norberto Hernández, El "nuevo" acuerdo final para la paz a través del lente del derecho penal, 13 Revista Nuevo Foro Penal, n. ${ }^{\circ} 88,217-239$ (2017). https://doi.org/10.17230/nfp.13.88.7

Octavio Nájera, La construcción del concepto de víctima en el neoliberalismo, en Política criminal mediática. Populismo penal, criminología crítica de los medios y de la justicia penal, 703-721 (Estanislao Escalante coord., Grupo Editorial Ibáñez, 2018).

Rodrigo Uprimny, \& Maria Paula Saffon, Usos y abusos de la justicia transicional en Colombia, Anuario de derechos humanos, n. ${ }^{\circ} 4$, 165-195 (2008). https://doi.org/10.5354/0718-2279.2008.13511

Ruti Teitel, Transitional Justice (Oxford University Press, 2002).

Yesid Reyes, ¿Es injusta la justicia transicional? A manera de estudio preliminar, en ¿Es injusta la justicia transicional?, 13-33 (Yesid Reyes ed., Universidad Externado de Colombia, 2018).

Yesid Reyes, Víctimas, fin y necesidad de la pena en el Derecho penal y en la llamada justicia transicional, en La influencia de las víctimas en el tratamiento jurídico de la violencia colectiva, 187-205, (Alicia Gil \& Elena Maculan Coord., 2017).

\section{Notas}

[1] Como lo explica Sampedro, la noción de víctima del delito supera su correlación con el sujeto pasivo del delito e incluye a los perjudicados (directos e indirectos) y la sociedad. Julio Sampedro, La rehumanización del sistema penal. Una propuesta desde las víctimas y la justicia restaurativa, 59 (Pontificia Universidad Javeriana, Equion Energía para la vida, Instituto Berg de Derechos Humanos, Grupo Editorial Ibáñez, 2019). Para Nájera, debe realizarse una reconfiguración del concepto de víctima en el neoliberalismo, incluyendo víctimas de desastres naturales, víctimas del sistema penal, víctimas de daños colaterales por vivir en una sociedad de riesgo constante e incluso, aquellos que son criminalizados. Octavio Nájera, La construcción del concepto de víctima en el neoliberalismo, en Política criminal mediática. Populismo penal, criminología crítica de los medios y de la justicia penal, 703-721, 717-718 (Estanislao Escalante coord., Grupo Editorial Ibáñez, 2018). Esto será importante para el reconocimiento de la calidad de víctimas que deberá otorgar la sala o sección respectiva (artículo $3^{\circ}$, Ley 1922 de 2018) y en especial la Sala de Definición de Situaciones Jurídicas, en virtud de lo normado en el artículo 48 de la misma ley. Sobre la acreditación de las víctimas ante la JEP ver los fundamentos Nos. 127 y 128 de la sentencia interpretativa del 3 de abril de 2019 (TP-SA-SENIT 1 de 2019) de la Sección de Apelación del Tribunal para la Paz de la JEP. 
[2] I Claus Roxin, Derecho penal. Parte General. Fundamentos de la estructura de la teoría del delito, 108 (Diego Manuel Luzón Peña, Miguel Díaz, et al. trads., Civitas, 1999).

[3] En sentido similar la propuesta de Julio Sampedro, La rehumanización del sistema penal, op. cit., 27, 210,235 y 243.

[4] "La Corporación [Corte Constitucional] ha explicado el contenido de la justicia transicional como un conjunto amplio de procesos y mecanismos, judiciales y no judiciales, de carácter excepcional y transitorio, que responden a largos periodos de violencia generalizada, en los que se han cometido constantes violaciones de derechos humanos y al derecho internacional humanitario. Los propósitos de la justicia transicional son: (i) responder a la violencia generalizada y, por ende, asegurar el derecho a la paz; (ii) garantizar los derechos de las víctimas a la verdad, la justicia, la reparación y la no repetición de los hechos violentos; (iii) fortalecer al Estado de derecho y a la democracia; $y$ (iv) promover la reconciliación social". Sentencia C-007/18. Respecto al modelo de justicia transicional colombiano ver Rodrigo Uprimny, \& Maria Paula Saffon, Usos y abusos de la justicia transicional en Colombia, Anuario de Derechos Humanos, n. ${ }^{\circ}$ 4, 165-195 (2008). También Lorena Vega, Modelo de justicia transicional: el caso colombiano, en Retos en la implementación de los acuerdos de paz en Colombia,111-130 (Gerardo Ruiz, Ildiko Szegedy y Rafael Prieto eds., 2018).

[5] Contrario sensu, el título IX de la LE-JEP consagra unos parámetros más exhaustivos en torno a la imposición de las sanciones que incluye criterios para su dosificación, actividades susceptibles de reconocimiento por parte de la JEP como cumplimiento anticipado de las sanciones y una tipología de sanciones que se pueden aplicar a los responsables, reiterando en el artículo 125 que una de las finalidades esenciales de las mismas es satisfacer los derechos de las víctimas. Igualmente se insiste en la función restaurativa y reparadora del daño causado que deberán tener aquellas.

[6] Norberto Hernández, El fracaso de la resocialización en Colombia, Revista de Derecho, n. ${ }^{\circ}$ 49, 1-41 (2018). Ambos matizan esta afirmación, asegurando que los resultados de la resocialización son "bastante desalentadores" Kai Ambos, Sobre los fines de la pena al nivel nacional y supranacional, Revista de Derecho Penal y Criminología, n. ${ }^{\circ}$ 12, 202 (2003).

[7] Claus Roxin, op. cit., 81 .

[8] Advertía Gallego: "Recordemos que no se está negociando con una guerrilla derrotada (en ese caso no habría negociación, sino sólo aplicación de la legislación ordinaria en una situación de sometimiento a la justicia), sino con una guerrilla que, aunque debilitada, sigue teniendo capacidad militar para continuar con su estrategia de guerra de guerrillas, asestar golpes al Ejército y a las infraestructuras y mantener el control sobre áreas del territorio nacional” Gloria Gallego, Perdón y proceso depaz en Colombia, 12 Revista Nuevo Foro Penal, n. ${ }^{\circ} 87,159-180$ (2016). En esta misma línea, señala Reyes: "Neumann considera que cuando esta superación del conflicto se consigue por medio de un acuerdo (y se menciona específicamente el caso de Colombia), cada una de las partes debe pagarlo con concesiones que, en el ámbito del derecho penal, pueden llegar hasta a la renuncia del castigo". Yesid Reyes, ¿Es injusta la justicia transicional? A manera de estudio preliminar, en ¿Es injusta la justicia transicional?, 13-33, 17 (Yesid Reyes ed., Universidad Externado de Colombia, 2018). Congruente con lo anterior, Murillo expresa: "no es razonable pensar que este proceso de negociación pueda terminar en un acuerdo en el que lo único que se ofrezca a los combatientes sea una prisión en la que estarían encerrados por décadas, por ello es inevitable reducir el imperativo de castigo total en beneficio de la paz" I Adolfo Murillo, Justicia transicional y fines de la pena en el contexto colombiano, en Contribuciones al derecho contemporáneo, en Derechos Humanos y Justicia Transicional 149-174, 167 (Diego Tarapués \& Adolfo Murillo coord., 2018).

[9] Excepcionalmente no se cumple esta estructura, que es lo que se conoce como normas incompletas. En este sentido ver I Alfonso Reyes, Obras completas, 43 (Temis, 1998); Álvaro Pérez, Introducción al derecho penal, 194 (Temis, 2009) y Fernando Velásquez, Manual de derecho penal. Parte general, 146 (2010).

[10] Norberto Hernández, El derecho penal de la cárcel. Una mirada al contexto colombiano con base en el giro punitivo y la tendencia al mayor encarcelamiento, 31 (Siglo del Hombre Editores, Universidad de los Andes, Universidad EAFIT, 2018). *Este supuesto será utilizado a lo largo del documento, omitiendo la referencia a otras penas diferentes a la privativa de la libertad.

[11] Esta tabla \#modificada en este documento con base en la sanción presidencial de la Ley 1957 de 2019\# se había realizado en Norberto Hernández, El "nuevo" acuerdo final para la paz a través del lente del derecho penal, 13 Revista Nuevo Foro Penal, n. ${ }^{\circ} 88,217-239$ (2017).

[12] Conforme el art. 125 de la LE-JEP las sanciones buscan satisfacer los derechos de las víctimas y consolidar la paz, razón por la cual se da por descontadas estas finalidades en la tabla y serán desarrolladas más adelante en el documento. También consideramos que, a pesar de encontrarnos en un contexto de transición, todas estas sanciones cumplen fines preventivos, lo cual será parte fundamental para la tesis que se propone en este trabajo.

[13] En virtud de la remisión que se hace al artículo 84, literal h de la LE-JEP.

[14] Así se ratificó en la sentencia C-080/18.

[15] La jurisprudencia constitucional tampoco hace distinciones al respecto (Cfr. Sentencias C-489/96, C-088/02, C-232/02, C-392/02, C-689/02, C-1080/02, C-652/03, C-798/08, C-575/09, C-434/13, C-239/14, C-368/14, C-102/15, C-191/16, C-259/16, C-539/16, C-041/17 y C-007/18) e incluso cataloga al decomiso como una sanción penal ( $C f$ r. Sentencia C-764/02). Ahora bien, aunque desborda el objetivo de este trabajo, se debe hacer alusión al sistema de responsabilidad penal para adolescentes, donde en vez de penas se habla de sanciones (Capítulo V, Ley 1098 de 2006). 
Por otra parte, también se habla de sanciones administrativas. Sobre esto último ver David Suarez \& Laura Restrepo, Comparativo de cinco procedimientos administrativos sancionatorios (Fase II): Faltas - Sanciones - Etapas - Segunda Instancia - Principios, 4 Summa Iuris, n..$^{\circ}$ 2, 224-250 (2016).

[16] "Admitiendo que en los procesos de transición la aplicación de sanciones penales constituye solo una de sus herramientas, resulta válido preguntarse si es legitimo imponer sanciones atenuadas frente a las que consagra la justicia ordinaria. Para resolver de manera adecuada este interrogante debe retomarse el tema de la finalidad de las sanciones penales; si se admite que el derecho penal es un instrumento de control social, las penas deben ser más que una manifestación de retribución por el mal causado, pues de lo contrario no serian más que una forma (estatal) de venganza”. Yesid Reyes, ¿Es injusta la justicia transicional? A manera de estudio preliminar, op. cit., 13-33, 22.

[17] Elena Larrauri, Introducción a la criminología y al sistema penal, 22 (Trotta, 2015).

[18] El Código Penitenciario y Carcelario colombiano hace una diferenciación entre cárcel y penitenciaría, encontrándose destinada la primera para los sindicados y la segunda para los condenados. En este trabajo se omitirá esta diferenciación técnica utilizando indistintamente los términos, "cárcel", "penitenciaría", "penal" "prisión" o "centro de reclusión", recurriendo de manera preponderante al primero de estos vocablos, por ser más común y didáctico para el objetivo perseguido.

[19] "Las sanciones propias no se cumplen dentro del sistema carcelario y penitenciario ordinario, es decir, la sanción propia no es privativa de la libertad en términos convencionales, sino restrictiva de libertad" Sentencia C-080/18.

[20] De conformidad con lo dispuesto en el art. 127 de la LE-JEP, en concordancia con el inciso segundo del art. 64 de la Ley 1922 de 2018, para determinar las condiciones de la restricción efectiva de la libertad, se tendrán en cuenta los siguientes criterios: (i) fijación de espacios y horarios para el cumplimiento de las sanciones; (ii) fijación de lugares de residencia; e (iii) indicación del órgano de verificación.

[21] La Agencia para la Reincorporación y la Normalizaciónreporta 12 entornos productivos implementados y 677 personas vinculadas (estadísticas a junio de 2019).

[22] Kai Ambos, op. cit., 198, Nota al pie 32.

[23] Luisa Caldas, Aproximación a los problemas fundamentales de la justicia transicional. Especial énfasis en las sanciones imponibles en el marco de la jurisdicción especial para la paz, 37 Derecho Penal y Criminología, n. ${ }^{\circ}$ 102, 111 (2016); Yesid Reyes, Víctimas, fin y necesidad de la pena en el Derecho penal y en la llamada justicia transicional, en La influencia de las víctimas en el tratamiento jurídico de la violencia colectiva, 187-205, 189-197 (Alicia Gil \& Elena Maculan Coord., 2017) y Adolfo Murillo, op. cit., 149-174, 156-167.

[24] En el mismo sentido Alicia Gil, Sobre la satisfacción de la víctima como fin de la pena, Indret: Revista para el Análisis del Derecho, n. ${ }^{\circ}$ 4, 2 (2016).

[25] Deliberadamente omitiré el análisis del enfoque materialista o político por contener una crítica extensa que desborda los objetivos de este trabajo. En todo caso, en una breve mención al respecto, para motivar al lector a profundizar sobre el tema, es importante señalar que en este enfoque se analizan "los determinantes económicos y políticos de la política penal, el papel de las instituciones penales en las estrategias de dominio de clase, y las maneras en que la penalidad sirve para expresar tanto simbólica como materialmente el poder del Estado" David Garland, Castigo y sociedad moderna. Un estudio de teoría social, 105 (Berta Ruiz trad., Siglo XXI Editores, 1999).

[26] Alessandro Baratta, Criminología crítica y crítica del derecho penal (Siglo XXI editores, 1989).

[27] I Iñaki Rivera, La cuestión carcelaria. Historia, Epistemología, Derecho y Política penitenciaria (Editores del Puerto, 2006). "Consideramos apropiado hablar de fines de la pena, y no de funciones; en reiteradas ocasiones la doctrina ha señalado que cuando se habla de función de la pena se hace referencia al ser, es decir, al por qué se impone una pena; o, como lo ha señalado el profesor Bustos, la función de la pena en un Estado social y democrático de derecho no es otra que la autoconstatación del propio sistema, mediante la cual se protegen bienes jurídicos que se han fijado como producto de las relaciones sociales; por el contrario, cuando se habla de fines de la pena se hace referencia al deber ser, qué busca el Estado con la imposición de una pena, respondiendo a la pregunta para qué" Carmen Ruiz, Lección 2: Teoría de los fines de la pena, en Lecciones de derecho penal. Parte General, 29-42 (2011).

[28] Norberto Hernández, op. cit., 337. Para el caso colombiano, el art. $4^{\circ}$ del C.P. establece que la pena cumplirá las funciones de prevención general, retribución justa, prevención especial, reinserción social y protección al condenado.

[29] En el mismo sentido Luigi Ferrajoli, Derecho y razón. Teoría del garantismo penal, 263 (Perfecto Ibañez, Alfonso Ruiz, Juan Carlos Bayón, Juan Terradillos y Rocio Cantarero, trads., Trotta, 2009) y Claus Roxin, op. cit., 93.

[30] Georg Rusche \& Otto Kirchhmeimer, Pena y estructura social, 72 (Emilio Garcia trad., Temis, 1984).

[31] Contrario sensu, las teorías relativas justifican las penas como un medio para la realización de un fin utilitario de la prevención de futuros delitos, quedando consagradas entre estas, la prevención especial y la prevención general. Cfr. Luigi Ferrajoli, op. cit., 253 y Claus Roxin, op. cit., 85.

[32] A pesar que se atribuye a Kant y a Hegel la fuente de inspiración de esta teoría, la misma ya había sido teorizada por Campanella, Selden, Leibniz y Genovesi. Cfr. Luigi Ferrajoli, op. cit., 255.

[33] Claus Roxin, op. cit., 82-83; Juan Bustos \& Hernan Homazabal, Nuevo sistema de derecho pena, 541 (Trotta, 2004). 
[34] Alicia Gil, op. cit., 16.

[35] Elena Larrauri, op. cit., 56.

[36] José Cid, Prevención de delitos y utilitarismo: una confusión censurable (apropósito de "censurary castigar" de A. von Hirsch, Jueces para la democracia, n. ${ }^{\circ} 35,21$ (1999).

[37] Andrew von Hirsch, Censure and sanctions, 17 (Clarendon Press, 1993).

[38] Elena Larrauri, op. cit., 57.

[39] Andrew von Hirsch, Censurar y Castigar, 17 (Elena Larrauri, Madrid trad., Trotta, 1998).

[40] Dentro de esta corriente se podría ubicar a Ferrajoli, quien consagra penas cuyo máximo no supere los 10 años de prisión. $C f r$. Luigi Ferrajoli, op. cit., 414. Las penas máximas de 20 años que se consagran en virtud del Acuerdo, podrían acercarse a este criterio.

[41] Norberto Hernández, op. cit., 287.

[42] “(...) de un lado, la sanción será retributiva, porque implica restricción de derechos y libertades bajo estrictas condiciones de supervisión durante el tiempo en que dicha sanción deba ser cumplida. De otro lado, la sanción será restaurativa, pues asegurará el cumplimiento de funciones reparadoras por parte de los responsables, partiendo de su reconocimiento de responsabilidad, y siguiendo con el desarrollo de proyectos de interés social y de reparación”. Sentencia C-080/18.

[43] Claus Roxin, op. cit., 89 (1999). En otras palabras: "actúan sobre los que no han delinquido" Eugenio Zaffaroni, Alejandro Alagia, \& Alejandro Slokar, Derecho Penal. Parte General, 53 (Ediar, 2000).

[44] Günther Jakobs, Derecho Penal. Parte General. Fundamentos y Teoría de la Imputación, 26 (J. Cuellos y J. Serrano trads., Marcial Pons, 1995).

[45] Jeremías Bentham, El panóptico, La piqueta, 34-35 (1979).

[46] Cesare Beccaria, De los delitos y de las penas, 60-61 (J.A. de las Casas, trad., Alianza, 1982).

[47] Cesare Beccaria, op. cit., 71-72.

[48] Para Beccaria era más importante la certeza que la severidad de las penas. Elena Larrauri, op. cit., 51.

[49] Cesare Beccaria, op. cit., 72.

[50] Claus Roxin, op. cit., 91-92. Ferrajoli, por su parte, los comprende en el reforzamiento de la fidelidad al estado y la promoción del conformismo a las conductas. Luigi Ferrajoli, op. cit., 275.

[51] Massimo Pavarini, 'Economía del exceso' y castigos excesivos, Bulletin de la Société internationale de défense sociale pour une politique criminelle humaniste, n. $^{\circ}$ 30, 241 (2003).

[52] Luigi Ferrajoli, op. cit. 275.

[53] Manuel Cancio, Dogmática y politica criminal en una teoría funcional del delito, en El sistema funcionalista de derecho penal. Ponencias presentadas en el II Curso Internacional de Derecho Penal (Lima, 29, 31 de agosto y 01 de setiembre de 2000), Günther Jakobs y Manuel Cancio, Grijley, Lima, 34 (2000).

[54] Kai Ambos, op. cit., 207.

[55] Claus Roxin, op. cit., 85-92.

[56] Sobra advertir que la privación de la libertad en un establecimiento penitenciario y carcelario no logra incapacitar al sujeto para la comisión de delitos. Para un estudio al respecto en las cárceles latinoamericanas ver Insigth crime, El dilema de las prisiones: incubadoras del crimen organizado en Latinoamérica (2017). Sobre las cárceles como "Universidad del delito" ver Norberto Hernández, op. cit., 16; Julio Sampedro, Apuntes sobre la resocialización en el sistema penitenciario colombiano, Eguzkilore: Cuaderno del Instituto Vasco de Criminología, n. ํ 12, 109 (1998).

[57] Luigi Ferrajoli, op. cit., 226.

[58] Eugenio Zaffaroni, Alejandro Alagia y Alejandro Slokar, op. cit., 54.

[59] Ruti Teitel, Transitional Justice, 67 (Oxford University Press, 2002).

[60] En sentido similar Alicia Gil,op. cit., 12.

[61] En el Fundamento n. ${ }^{\circ}$ 68, de la Sentencia interpretativa del 3 de abril de 2019 (TP-SA-SENIT 1 de 2019) sobre "Beneficios provisionales, régimen de condicionalidad y participación de victimas", la Sección de Apelación del Tribunal para la Paz de la JEP advierte: "La desatención de los derechos de las víctimas y la reducción de su participación corre el riesgo de tener un segundo efecto nocivo, como el de erosionar toda posibilidad para alcanzar la paz. Desoír sus reivindicaciones frustraría la reconciliación nacional y la convivencia pacífica, al dejar abiertas las fisuras que el conflicto produjo sobre el tejido social. Las víctimas no intervienen en el modelo transicional solo para obtener justicia en causa propia -que es por supuesto una necesidad de suma importancia. Son sujetos activos y, al igual que otros colombianos, tienen derecho a contribuir en la recomposición de una sociedad fragmentada. Para esto, necesitan un espacio de encuentro con sus agresores, que hasta donde ello sea posible sirva para construir un relato del pasado. De ese ejercicio, que deberá realizarse en el apropiado momento procesal, depende la reanudación de la convivencia pacífica. El proyecto de reconciliación estaría evidentemente incompleto sin la presencia de las víctimas. En su ausencia, no se podrá ni sembrar ni cosechar la paz" (Resaltado fuera del texto). En sentido similar la propuesta de Sampedro, sobre "el proceso penal recreador". Julio Sampedro, La rehumanización del sistema penal, op. cit., $210-212$.

[62] En el mismo sentido lo reitera el art. $5^{\circ}$ de la Ley 1820 de 2016. 
[63] Sentencias C-579/13 y C-379/16.

[64] Sentencia C-007/18.

[65] Kai Ambos, op. cit., 208-209.

[66] Yesid Reyes, Víctimas, fin y necesidad de la pena en el Derecho penal y en la llamada justicia transicional, op. cit., 187-205, $197,198,201$ y 204.

[67] Íd., 204.

[68] Sentencias C-577 de 2014. M.P. (e) Martha Victoria Sáchica Méndez y C-379 de 2016. M.P. Luis Ernesto Vargas Silva.

[69] Específicamente, la Corte ha precisado que "[1]a reconciliación, así vista, apunta a vivir en comunidad teniendo la posibilidad de plantear las distintas posturas ideológicas en un contexto de respeto mutuo y concertación, por lo que la misma debe fundarse y desarrollarse sobre la existencia de niveles aceptables -y suficientes, de acuerdo con los requerimientos de cada sociedad- de deliberación pública, lo que implica la necesidad de que en la práctica se realicen concesiones a los actores que se integrarán a la comunidad que decide sobre los asuntos que constituyen la razón pública”. Sentencias C-577 de 2014. M.P. (e) Martha Victoria Sáchica Méndez y C-379 de 2016. M.P. Luis Ernesto Vargas Silva.

[70] $\mathrm{Al}$ respecto, la Corte ha señalado que "[e]l reconstruir la sociedad lleva consigo que se reconozca que aunque los actos violentos del pasado no pueden ser olvidados y por lo tanto deben ser conocidos, sancionados y sus víctimas reparadas,[...] en el marco de un conflicto interno, las posiciones enfrentadas deben incorporarse a la sociedad que toma las decisiones políticas, para de este modo vincularla al proceso democrático [...y] disminuir las posibilidades de que dichos actores, o miembros disidentes de ellos, continúen o posteriormente retomen la confrontación violenta como respuesta a la falta de canales democráticos de expresión para sus ideas." Sentencia C-577 de 2014. M.P. (e) Martha Victoria Sáchica Méndez. De igual manera, la Corte ha insistido en que el fortalecimiento de la democracia es una finalidad central de la transición hacia la paz, la cual se logra "mediante la promoción de la participación de todos, restaurando una cultura política democrática y un nivel básico de solidaridad y de confianza sociales para convencer a los ciudadanos de que participen en sus instituciones políticas por razones distintas a la conveniencia personal". Sentencia C-379 de 2016. M.P. Luis Ernesto Vargas Silva.

[71] Sobre el tema ver Alicia Gil, op. cit., 5-6 y Norberto Hernández, El discurso protector de las víctimas. Populismo punitivo en España y Colombia, 59 Revista Criminalidad, n. ${ }^{\circ}$ 1, 117-127 (2017).

[72] Yesid Reyes, Víctimas, fin y necesidad de la pena en el Derecho penal y en la llamada justicia transicional, op. cit., 195.

[73] David Garland, op. cit, 22.

[74] Para Sampedro, los modelos de respuesta al delito se concretan en tres: (i) el diasuasorio, (ii) resocializador y (iii) integrador. Julio Sampedro, La rehumanización del sistema penal, op. cit., 195.

[75] Elena Larrauri, op. cit., 176.

[76] Martin Wasik, \& Andrew von Hirsch, Non-custodial penalties and the principles of desert, 32 The Criminal Law Review, 555-572 (1998).

[77] Jose Cid, La elección del castigo, 29 (Bosch, 2009)

[78] En Colombia, a pesar de que la resocialización no está consagrada constitucionalmente como fin de la pena, en el Código Penitenciario y Carcelario (Ley 65 de 1993) se consagra este como su fin fundamental. Adicionalmente, el principio de resocialización es consustancial al esquema de Estado Social de Derecho implementado en la Constitución Política de 1991. De lo anterior se desprende que dentro de los modelos punitivos para la elección del castigo, Colombia - siguiendo el mandato del Pacto Internacional de Derechos Civiles y Políticos (artículo 10-3), que se integra a nuestra Constitución por vía del bloque de constitucionalidad - , adopta un estándar dirigido hacia la rehabilitación del penado y busca que el individuo no vuelva a delinquir en el futuro, para lo cual se deben abordar los factores específicos que lo vinculan con la comisión de delitos. Norberto Hernández, op. cit., 336-337.

[79] Francis Cullen \& Karen Gilbert, Reaffirming Rehabilition, (Anderson Publishing, 1981).

[80] Jose Cid, op. cit., 30.

[81] Michel Foucault, Vigilar y castigar. Nacimiento de la prisión, 75 (Siglo XXI Editores, 1976).

[82] Jose Cid, op. cit., 30.

[83] Lisa Stolzenberg, \& Stewart J. D'Alessio, "Three Strikes and You're Out": The impact of Californian's new mandatory sentencing law on serious crime rates, 43 Crime \& Delinquency, n. ${ }^{\circ} 4,457-469$ (1997).

[84] Elena Larrauri, op. cit., 61.

[85] John Braithwaite, Restorative justice and responsive regulation (Oxford University Press, 2002)

[86] Jose Cid, op. cit., 30.

[87] John Braithwaite, Crime, Shame and Reintegration, 226 (Cambridge University Press, 1989).

[88] Michel Foucault, La sociedad punitiva, en La vida de los hombres infames, 25 (La piqueta, 1990).

[89] Howard Zehr, El pequeño libro de la justicia restaurativa, 6 (Good Books, 2010).

[90] Julio Sampedro, La rehumanización del sistema penal, op. cit., 231. 
[91] En este sentido la sentencia interpretativa del 3 de abril de 2019 (TP-SA-SENIT 1 de 2019) sobre "Beneficios provisionales, régimen de condicionalidad y participación de víctimas” de la Sección de Apelación del Tribunal para la Paz de la JEP, fundamentos Nos. 64-78, 118, 120, 130

[92] De conformidad con el informe de la Comisión Internacional de Juristas de junio de 2019, la participación efectiva de las víctimas es uno de los desafíos de la JEP. Este análisis es objeto de otro documento de investigación del autor. Sobre el carácter dialógico del procedimiento ante la JEP, se puede consultar el artículo de Gustavo Cote que hace parte de esta compilación.

[93] No se aplica este sistema cuando se trata de preacuerdos y negociaciones con la Fiscalía (art. $3^{\circ}$ de la Ley 890 de 2004 ) siempre y cuando las partes acuerden el monto de la pena. Cfr. Sentencia del 20 de septiembre de 2016, Corte Suprema de Justicia, Sala de Casación Penal, Radicado 47588 [SP-133502016].

[94] Cuando se trate de delitos tentados se debe tener en cuenta el mayor o menor grado de aproximación al momento consumativo y en la complicidad el mayor o menor grado de eficacia de la contribución o ayuda.

[95] Equivalente a 27 años y 6 meses.

* Artículo de investigaciónUna versión preliminar de este artículo fue discutida en el seminario workshop Ley de Procedimiento de la Jurisdicción Especial para la Paz: aciertos, debilidades y desafios del derecho penal en contextos de justicia Transicional realizado los días 27 y 28 de mayo de 2019 en la Pontificia Universidad Javeriana. Con base en los comentarios allí suscitados y el advenimiento de la sanción presidencial de la Ley 1957 de 2019 [Estatutaria de la Jurisdicción Especial para la paz (en lo sucesivo LE-JEP)], el artículo fue modificado durante la estancia de investigación realizada por el autor en la Universidad de Salamanca (2019-2), la cual fue financiada por la Pontificia Universidad Javeriana. Agradezco a los participantes del seminario sus aportes para mejorar este documento; en todo caso hago la salvedad que las posibles imprecisiones con que se tope el lector a lo largo del mismo son enteramente responsabilidad del autor.

\section{Licencia Creative Commons CC BY 4.0}

Cómo citar este artículo: Norberto Hernández Jiménez, De la privación a la restricción de la libertad y otras sanciones penales: ¿hacia un paradigma restaurativo en la justicia especial para la paz colombiana?, 69 Vniversitas (2020). https://doi.org/10.11144/Javeriana.vj69.prls 